\title{
SIMULATION MODELLING AND STRATEGIC CHANGE: CREATING THE SUSTAINABLE ENTERPRISE
}

\author{
Patrick Dawson \\ Trevor Spedding \\ School of Management and Marketing \\ University of Wollongong
}

\begin{abstract}
This paper highlights the benefits of using discrete event simulation models for developing change management frameworks which facilitate productivity and environmental improvements in order to create a sustainable enterprise. There is an increasing need for organisations to be more socially and environmentally responsible, however these objectives cannot be realised in isolation of the strategic, operations and business objectives of the enterprise. Discrete Event Simulation models facilitate a multidimensional approach to enterprise modelling which can integrate operations and strategic considerations with environmental and social issues. Moreover these models can provide a dynamic roadmap for implementing a change strategy for realising the optimal conditions for operational and environmental performance. It is important to note that the nature of change is itself dynamic and that simulation models are capable of characterising the dynamics of the change process. The paper argues that incorporating social and environmental challenges into a strategic business model for an enterprise can result in improved profits and long term viability and that a multidimensional simulation approach can support decision making throughout the change process to more effectively achieve these goals.
\end{abstract}

\section{INTRODUCTION}

In examining simulation modelling and strategic change this paper addresses the question of how to create a sustainable enterprise. We contend that once a need for change has been established then there is design space within which options for improvements and potential developments can be considered. This is an area well suited to simulation modelling in which a range of options can be evaluated against one of a number of performance indicators. The identification of these performance indicators is influenced by strategic choices (Child, 1972 and 1997) and whether for example; the aim is for short-term commercial gain or for longer-term sustainable enterprise. We suggest that these decisions and assessments are not 'value-free' in any objective sense, but rather 
reflect the aims and ambitions of those in the position to make these strategic decisions. It is perhaps ironic that myopic strategies that seek simply to secure immediate profit maximisation can in practice, jeopardise longer-term business survival. From our perspective, sustainability is in many cases a far more commercially viable proposition for the business in the medium to longer term than adopting a management strategy which is based purely on profit and this in turn, highlights the value of simulation modeling in accessing options for change. In other words, whilst there are often value judgments caught up with notions of environmental sustainability (that is, it is often not seen as 'value free') we contend that this can often lead people to overlook the business case for such initiatives (that is, they can be both low cost - or even 'cost free' - and profitable). Through implementing practices that are environmentally 'friendly' and sustainable the savings from reduced costs through reductions in scrap, rework, resource consumption and the like, can offset the costs of implementing change and bring about long-term business benefits. Multidimensional simulation models can integrate environmental and social issues with business and operational practices so that a balanced and sustainable model of an enterprise can be derived.

In our discussion of simulation modeling and strategic change we commence with a simple conceptual schema of the change process. The process of strategic decision-making is outlined and the value of incorporating simulation analysis during these initial stages of change is emphasized. We then move on to a more detailed analysis of simulation modeling in which we identify and discuss various environmental issues that need to be taken into account; including: natural resource consumption, energy consumption, scrap and waste levels, pollution and the transportation of material between industries. After demonstrating the business case for change, we then present a processual framework that can be used to understand and guide the difficult and complex task of implementation. We then present eight practical lessons and critical reflections on the uptake of new business arrangements that support sustainable enterprise.

\section{MANAGING SUSTAINABLE CHANGE}

In analysing change over time, it is advocated that the timeframe of before, during and after change can be used as a means of breaking down the complex change process for analytical purposes. This framework mirrors the work of Beckhard and Harris (1987) who characterise organizational transition as a movement from a present state of organization to some future state (the process of getting from position A to position B). The three general categories advocated here comprise: the initial conception of a need to change; the process of strategic decision-making; and the implementation of new work practices and procedures.

The initial awareness of a need to change may either be in response to external or internal pressures for change (reactive), or through a belief in the need for change to meet future competitive demands (proactive). The increased complexity and uncertainty of international business markets has led some organizations to base change on imitation (which organizations are successful and what changes have they introduced), rather than on any conception of a need to adopt untried technologies or techniques (DiMaggio and Powell, 1991 and 1983). This conception of a need to change can be influenced by factors residing within the organization, such as operational inefficiencies or employee disputes, or by factors which emanate from outside of an organization for example, through business press and media reports on the success of other organizations and the direct or indirect promotion of various management techniques (Jackson, 2001). 
Once a need for change has been identified, then the complex non-linear and 'black box' process of strategic decision-making commences. This period will comprise a number of different tasks, activities and decisions for individuals and groups both within and outside of the organization (Dawson, 1993a). In order to clarify this statement let us take the example of a firm where senior management have identified a need to change to meet competitive pressures and a fall in profitability. Once a decision to change has been made, management then have to decide on the type of change they wish to introduce. This may be through a change in human resources, products or services (task), technology, or administration. In the case of new technology, a number of strategic objectives have been identified as influencing management's decision to embark on a programme of change. For example, a change in technology may offer several possibilities for increasing an organization's ability to adapt to changing market conditions. The flexibility of advanced capital equipment may permit the modification and redesign of production without necessitating any major structural alterations to the operating system. Alternatively, the new technology may enable a more effective utilization of existing resources and increase operating efficiency whilst reducing overall operating costs, and thereby improve an organization's business market position. Such an objective is achievable in cases where modern technology is introduced for the purpose of providing rapid access to accurate, up-to-date information on the disposition of material resources.

Apart from improving a firm's market position and reducing operating costs through the more efficient utilization of resources, savings could also be made by reducing natural resource consumption and the amount of energy used in the production of a given good or service. Technology could also be used to improve the quality of business processes and thereby reduce scrap and waste levels. In this search for choices process modelling and simulation offers an ideal method for the assessment of options. This is further spotlighted by research that has shown how the formulation of strategic objectives is not always as clearly defined as one might often expect. For example, the research of James Quinn (1980) demonstrates how strategic decisions are often not highly formalized and may take the form of what he terms 'logical incrementalism'. This involves the blending of behavioural techniques, power politics and formal analysis, in a logical incremental movement towards ends that are broadly conceived and revised in the light of new information during the process of strategic change. Quinn's findings illustrate how strategies can often be implemented prior to their final formulation, in for example, the conceptualization phase (Quinn, 1989:20-36). This lends support to the need for simulation modelling that is able to provide evaluations of a number of different permutations for change. For example, when members of an organization set out to find the best option for achieving a particular change objective, the assessment task is likely to involve an analysis of a wide number of possible options/configurations for change. In practice, many of these decisions may have been made during the conception stage. Although, these may undergo revision as more information is collected through simulations that enable an evaluation of what costs are involved and what the pay-back on investment is likely to be. In this way, simulation exercises can support the process of strategic choice in the management of change. In the section below, we examine the use of simulation models as a vehicle for supporting strategic decisions. 


\section{SIMULATION MODELLING FOR SUSTAINABLE BUSINESS}

There are many computer based discrete event simulators that are well suited to modelling the variability, interrelationships and dynamics exhibited by manufacturing enterprises. These simulators allow complex organisations to be represented in the form of stochastic models built on a networked series of transformation systems. Models consist of entities (units of traffic), resources (elements that service entities), and control elements (elements that determine the states of the entities and resources). The simulation environment facilitates drag and drag and drop programming, and support features such as statistical modelling of input and output data, animation and virtual reality, optimisation, scenario analysis and experimental design.

Most simulation studies in manufacturing were originally designed to model productivity (see for example Law et al). This emphasis is reflected in the functionality of contemporary simulation systems such as Arena, Promodel and Witness. By extending these models to include other forms of analysis such as costing and quality (see for example Spedding and Chan 2001) a more comprehensive business model can be developed which can be used for operational and strategic decision making. Simulation models of enterprises have also been extended to include environmental issues including the emissions and energy consumption of production facilities and pollution due to logistics and transportation (see for example Khoo et al 2001 and Wohlgemuth 2006).

By integrating a multidimensional simulation of an enterprise in terms of cost, quality and productivity with environmental and social issues it is possible to present environmental and social sustainability in terms of a business case. One example of this approach was developed by the authors (Khoo 2006) of an end-to-end metal supply chain consisting of a generic refinery, a smelter and a metal feedstock producer (all based in Queensland, Australia) (Figure 1). The model simulates activities including material, product and information flow, cost (in terms of activity based costing), product and service quality, and environmental issues such as natural resource consumption, energy consumption, scrap and waste levels, pollution and the transportation of material between industries. These activities were modelled across and within each component of the supply chain so that a holistic systems approach could be obtained. Two models were developed, one representing the current state of the end-to-end supply chain and another representing a future state which incorporates productivity and environmental improvements. It is important to note that there is a significant correlation between best practice production techniques such as lean and six-sigma philosophies and sustainable practices and so productivity and environmental improvement are not independent. Through the integration of activity based management techniques the model facilitates the development of an evidence based business case for productivity and sustainable improvements in both the individual components of the enterprise as well as the supply chain as a whole. 


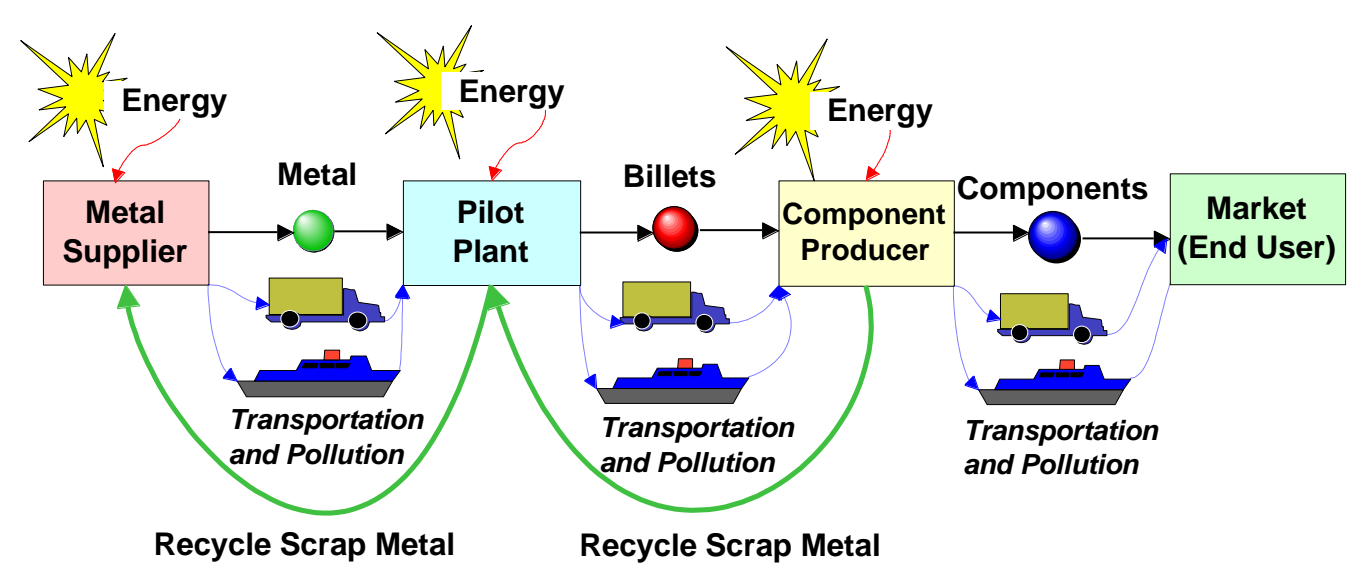

Figure 1 An End to End Metal Supply Chain

A limitation of this approach is that it results in two simulation models, one of the current state of the enterprise and another representing an optimal future state. It is therefore necessary to develop a change mechanism for moving from the current state to the desired optimum. Depending on the improvements required, this path may be straightforward or may involve a complex iterative transformation involving technological, social and cultural change. For example in may be necessary to adopt an innovative technology to facilitate a productivity improvement which is currently unreliable or may require a significant cultural change. It may therefore be necessary to design a phased implementation in which other system improvements are given priority until the desired level of reliability or cultural change is obtained

The dynamic nature of simulation modelling allows detailed implementation plans to be developed in terms of staged roadmaps for technological and cultural change and their interface. This is achieved by simulating the changes necessary to facilitate technological and cultural improvement and modelling the path to achieve a successful change process.

\section{The Process of Implementing Change}

The process of implementing change is taken to refer to the period when, following the decision to change, new organizational arrangements and systems of operation are implemented and new ways of doing things begin to emerge. During this period, a number of novel developments or contingencies may arise which may compromise the change. For example, unanticipated technical or social problems may undermine the usefulness of the system in its replacement of traditional methods. As a result, this may cause conflict and confusion among staff and management, and threaten the establishment of new working relationships. Thus, the early stages of change implementation may be characterised by uncertainty, conflict and misunderstanding among employees, who may variously adapt, modify, reassert and/or redefine their positions under new operating procedures and working relationships imposed as plans are rolled out across the organization. The task of managing these complex processes associated with implementing change has been identified as a period that requires considerable political skill on the part of the change 
agent (Buchanan and Badham, 2008; Buchanan, 2008). It is during the implementation of change programmes that occupational and employee concerns normally begin to influence the transition process (Dawson, 1994), these concerns may manifest themselves as a complex political struggle between various occupational groups (managerial, supervisory and operative) with differing vested interests (see also, Clausen, Dawson and Nielsen, 2000).

It is argued here that a useful way of tackling the problem of managing complex change processes is to group and identify the main determinants that shape these processes. In Dawsons (2003) processual approach these seem to comprise the politics, substance and context of change. Although every major change programme will have an organizationally defined beginning, middle, and end, in practice it is not only difficult to identify the start and completion of change programmes (for example, there is often more than one organizational history of change and these may be reconstructed over time) but also, to explain the complex pathways and routes to establishing new operational processes. Therefore, in examining the process of change there are considerable returns to be gained from developing a framework to support the implementation process.

The politics of change is taken to refer to the political activity of consultation, negotiation, conflict and resistance, which occurs at various levels within and outside an organization during the process of managing change. The context in which change takes place includes external contextual factors, such as: changes in competitors' strategies; level of international competition; government legislation; changing social expectations; technological innovations; and changes in the level of business activity; and internal contextual factors, such as: administrative structures, human resources, and the history and culture of an organization. The substance of change is seen to comprise four main elements: first, the scale and scope of change, which may range along a continuum from small-scale discrete change to a more 'radical' large-scale transformation. Second, the defining characteristics of the change programme: which refers both to the labels attached to change projects and the actual content of the change in question. Third, the timeframe of change: at it simplest this refers to the period over which change occurs from the conception of the need to change through to routine operation. Fourth, the perceived centrality of the change: that is whether or not change is seen to be critical to the survival of the organization. For example, if change is viewed as central to the competitive position of the company, then it can have major implications for the timescale, resource support and overall employee commitment to change. Finally, it should be noted that the substance of change is not static but is itself open to change. In other words, the substance of change both influences and is influenced by contextual and political elements. For example, it is not uncommon for definitional confusion to surround the introduction of change initiatives and for the content of change to be redefined during the process of implementation. Moreover, knowledge of the substance of change and clarification of what the change means for a particular organization can in itself become a political process, influenced by external contextual views and the setting of internal agendas around the management of change. In this sense, there is a continual interplay between these three groups of determinants during the process of managing change in organizations (see Dawson 2003). 


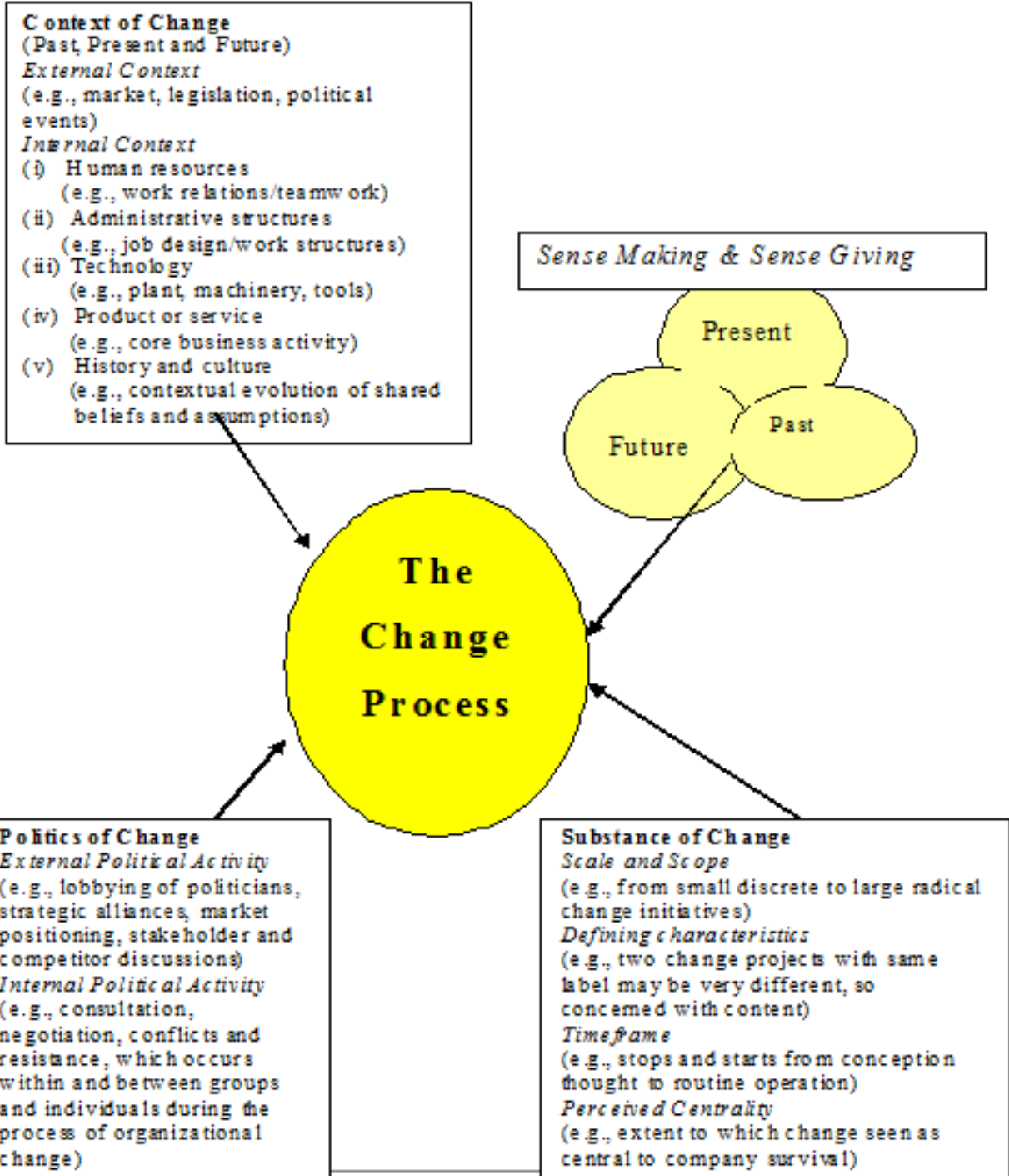

In using this framework to guide the implementation process (see Figure 2), there are a number of issues that require continual assessment as implementation teams are prepared for the unforeseen and are able to accommodate the unexpected. Technical and human contingencies require agile and flexible change agents that are able to adapt their prepared plans and to reconsider the appropriate routes for change. In charting the messy non-linear nature of change a good starting heuristic is that there are no universal prescriptions on how to best manage change. If there was a silver bullet on 
this issue all business organizations would be following similar road maps to 'successful' change. Another key element is the importance of being contextually away (to internal issues and to the external business environment) and to recognise that change agents need to be politically astute, as steering change in certain preferred directions generally requires a coalition of people - highlighting the need to seek support from all quarters. With regard to the substance of change, large radical change programmes rarely come in on time and in budget. Moreover, what constitutes change - the defining characteristics - can often change over time, but this should not be viewed negatively, as a broader understanding and definition of what the change comprises can bring about greater engagement and commitment to the change in question. Hypothetically, it is not possible to outline all the possible routes for all organization in the journey to creating the sustainable enterprise, but there are a number of practice lessons or critical reflections that can be drawn from this processual framework to understanding change. These are as follows:

1. There is no one best way. There are many ways to improve business performance and this includes environmentally sustainable change.

2. Look beyond short term wins. Successful environmental change takes time but can result in the achievement of longer term strategies for sustainable futures.

3. Involvement and ownership. The environmental route often appeals to the hearts and minds of employees. Communicate and collaborate on issues that need addressing in order to gain input and commitment in developing a shared approach.

4. Be flexible. Unforseen events highlight the need for flexible and reviewable implementation strategies.

5. Timely training of employees. Organise training and skill development to link with programme of change, not one-off.

6. Accommodate resistance. Listen, learn, engage and feedback and when necessary, modify your programme.

7. Be contextually aware. Account for external and internal contextual issues. Less tangible issues (such as public image of company) can significantly improve future business performance but are not easy to measure.

8. Seek support from all quarters. Recognise that change is a political process and requires the commitment, support and involvement by a coalition of people.

\section{CONCLUSION}

There is a growing impetus for organizations to examine the environmental implications of their business practices and to seek innovative ways to establish commercially viable sustainable enterprise. Throughout the media and political discourse there is increasing pressure on organisations to be more socially and environmentally responsible and accountable. These new business expectations mirror the increasing pressures on individuals and communities to take up more environmentally sustainable lifestyles and behaviours. There is a growing call for: more ethically transparent management practices, for greater corporate responsibility among business organizations, and for the need to create and maintain sustainable enterprise. In moving towards these objectives, consideration has to be given to the full range of options open to business and to the issues of implementing change to secure the objectives intended behind such strategic decisions. In our discussions, we have highlighted the value of simulation modelling and change management frameworks to furthering developments in this important and emerging area. 
The change management frameworks outlined in this paper can be integrated into simulation models to provide dynamic roadmaps which accurately reflect the mechanisms necessary to facilitate operational, technological, environmental and social change necessary to leverage optimal benefits for the enterprise. Simulation models are also capable of characterising the nature of change which in itself is dynamic. It is observed that developing a multidimensional simulation to support the creation of a sustainable enterprise has three distinct phases: (i) formulating an accurate representation of the current state of the enterprise, (ii) developing a optimal and sustainable future state which encompasses all aspects of the enterprise in terms of the business, operational, environmental and social functions and (iii) providing a dynamic road map based on change management frameworks to fully realise the future state of the company derived in phase two.

Traditionally, business innovations have focused on improving practical problems such as better tools, products and techniques to achieve competitive advantage. We contend that in the face of increasing economic, social and environmental challenges, contemporary societies are looking towards innovations that resolve these concerns, and in conjunction, improve the well-being of people. As argued, although there is an assumption that such concerns undermine hard competitive gains and in the process reduces profits whilst increasing costs; in practice, this has not proven to be the case and rather reflects a rather myopic short-termism to strategic development and change. Continuity and business survival requires strategic change that is both innovative and sustainable and increasingly, this necessitates a broader consideration of environmental issues. Whilst it is hard to take the first step - as if it has business value in competing for the future the question inevitably arises of: who else is doing it? There is a growing need to challenge traditional business models and cherished assumptions in creating new business challenges in securing a commercial market economy of sustainable enterprise.

\section{REFERENCES}

Andriopoulos, C. \& Dawson, P. 2009, Managing Change, Creativity \& Innovation, Sage, London.

Beckhard, R. \& Harris, R.T. 1987, Organizational Transitions: Managing Complex Change, 2nd edn, Addison_Wesley, Reading, MA.

Buchanan, D.A. 2008, 'You stab my back I'll stab yours: management experience and perceptions of organizational political behaviour', British Journal of Management, vol. 19, pp. 49-64.

Buchanan, D.A. \& Badham, R.J. 2008, Power, Politics, and Organizational Change: Winning the Turf Game, 2nd edn, Sage, London.

Child, J. 1997, 'Strategic choice in the analysis of action, structure, organizations and environment: retrospect and prospect', Organization Studies, vol. 18, no. 1, pp. 43-76.

Child, J. 1972, 'Organization structure, environment and performance: the role of strategic choice', Sociology, vol. 6, no. 1, pp. 1-22.

Clausen, C., Dawson, P. \& Nielsen, K.T. 2000, 'Political processes in management, organization and the social shaping of technology', Technology Analysis \& Strategic Management, vol. 12 , no. 1, pp. 1-143.

Dawson, P. 2003, Reshaping Change: A Processual Perspective, Routledge, London. 
DiMaggio, P. \& Powell, W. 1991, The New Institutionalism in Organisational Analysis, University of Chicago Press, London.

DiMaggio, P. \& Powell, W. 1983, 'The iron cage revisited: institutional isomorphism and collective rationality', American Sociological Review, vol. 48, pp. 147-60.

Jackson, B. 2001, Management Gurus and Management Fashions, Routledge, London.

Khoo, H.H., Spedding, T.A., Houston, D., and Taplin, D. 2001 “Application of Modelling and Simulation Tools in Costs and Pollution Monitoring" The Environmentalist, Vol 21 161-168

Khoo, H.H, Spedding, T.A. Bainbridge, I., and Taplin, D.M.R 2006 Creating A Green Supply Chain: A Simulation and Modelling Approach. in Greening the Supply Chain edited by Joseph Sarkis, Springer, London ISBN 978-1-84628-298-0 pages 341-361

Quinn, J.B. 1989, 'Managing strategic change', in Asch, D. \& Bowman, C. (eds.) Reading in Strategic Management, Macmillan, London.

Quinn, J.B. 1980, Strategies for Change: Logical Incrementalism, Irwin, Homewood.

Spedding, T.A. and Chan KK, 2001 "System Level Improvement using Discrete Event Simulation" International Journal of Quality and Reliability Management, Vol 18, No 1, 84-103

Wohlgemuth,V., Page,B. and Kreutzer, W 2006 Combining Discrete Event Simulation and Material Flow Analysis in a Component-Based Approach to Industrial Environmental Protection. Environmental Modelling \& Software Vol 21 1607-1617 